\title{
Accounting for demography in the assessment of wild animal welfare
}

\section{Author Information}

Luke B.B. Hecht ${ }^{1^{*}}$

${ }^{1}$ Department of Biosciences, Durham University, Durham, United Kingdom

*to whom correspondence should be addressed: luke.b.hecht@durham.ac.uk

\section{Address}

Luke Hecht

Department of Biosciences, Durham University

Stockton Road, Durham DH1 3LE

United Kingdom

\section{Acknowledgements}

I thank Wild Animal Initiative for their support of my research. I also thank Matthew Allcock and Brian Tomasik for their valuable feedback.

\section{Declaration of Interest}

I have no competing interests to declare. 


\section{Abstract}

Welfare is experienced by individual animals, but the quantity and average quality of welfare an individual is likely to experience in their lifetime is bounded by population demography; namely, age-specific survivorship and the ecological forces that shape it. In many species, a minority of the individuals who are born survive to adulthood, meaning that the lives of those we observe in nature are often unrepresentative of the typical individual born into their population. Since only living animals are capable of experiencing welfare, lifespan is effectively an upper bound on the amount of affectively positive or negative experience an animal can accrue. Life history strategies that increase the probability of a long life are therefore more permissive of good welfare; but even holding life expectancy constant, specific patterns of age-specific mortality may enable a larger proportion of individuals to live through periods characterized by aboveaverage welfare. I formalize this association between demography and welfare through the concept of welfare expectancy, which is applied to published demographic models for $>80$ species to illustrate the diversity of age-specific mortality patterns and entertain hypotheses about the relationship between demography and welfare.

The experiences of wild animals are extraordinarily diverse. Individuals of different species occupy different habitats, consume different resources, and engage in different behaviors. Even within species, animals' fortunes differ based on their relative fitness or due to chance events, leading to differential survival or mating success. While life history strategies evolve to maximize inclusive fitness, it is crucial to recognize that fitness and welfare are not the same (Beausoleil et al., 2018). For example, a strategy which maximizes mean fitness may do so while increasing the variance in outcomes among siblings, leading to reproductive success in adulthood for a few, but short lives for most (Pettorelli and Durant, 2007). Even for a successful individual, high evolutionary fitness need not imply good welfare, as sexual competition forces trade-offs between reproduction and survival or somatic maintenance (Johnston et al., 2013).

A key objective of the nascent fields of conservation welfare (Beausoleil et al., 2018) and welfare biology $(\mathrm{Ng}, 1995)$ is to evaluate the quality of lives lived by wild animals in order to identify causes of poor welfare, as well as safe and tractable interventions to improve welfare. Empirical evaluations of wild animal welfare, such as those based on stress hormone levels and other veterinary techniques, have been carried out, though few are comparable between contexts (Schwarzenberger, 2007). One of the most promising proposals to date is the use of differential rates of biological aging as an indicator of lifetime cumulative welfare under different conditions (Bateson and Poirier, 2019; Poirier et al., 2019). For example, social stress related to brood size and social rank has lifelong fitness consequences in birds that appear to be mediated by telomere attrition, a prominent biomarker of biological age (Boonekamp et al., 2014; Nettle et al., 2015). More generalized application of these methods will require

43 hypotheses to test and a framework for prioritizing which populations to evaluate and which 44 groups of individuals within them to potentially aid. 
A promising starting point is to reason from demographic patterns such as the distribution of individual lifespans. This approach is compatible with a wide range of assumptions about the causes and levels of wild animal welfare, since only living animals are capable of experiencing welfare. Moreover, the quality of life experienced by a typical week-old animal is likely different from that of a year-old animal due to changing levels of vulnerability to disease and predation, competition with conspecifics, self-sufficiency, and senescence.

Demographic patterns are observed at the population level but experienced by individuals. Population models can provide examples of potential demographies, and although no firm conclusions about welfare can be drawn from interspecific comparisons given our uncertainty about the preferences and experiences of most animals, we can use their diverse population dynamics to probe the implications of different hypotheses for how welfare varies with age.

Here, I set out a framework for incorporating demography in the evaluation of wild animal welfare based on the principle of expected value and formalize previously expressed intuitions about the relationship between life history and welfare. I also illustrate this by application to published matrix population models for 160 populations of $>80$ species and formulate working hypotheses about welfare to be tested by future field studies.

\section{Methods}

2.1 Matrix population models

Matrix population models (MPMs) use matrix algebra to represent transitions between life stages in a population (Caswell, 2001). They are widely used to infer populations' instantaneous rates of growth, as well as for estimating vital rates such as survival and fecundity, and conducting population viability analyses (Heppell et al., 2000). MPMs may be structured by age, stage, or another trait, such as size. For the analyses described here, I used exclusively agebased models to avoid any ambiguity around stage durations.

It is possible to calculate the expected distribution of lifespans among a cohort from the agespecific mortality rates given by an MPM. Life expectancy is then calculated as the sum of the probability of each possible lifespan multiplied by its length (Caswell, 2009). Annual survival probabilities were assumed to be the product of equal daily survival probabilities, so individuals dying during a given year were assumed to have lived through half of that year.

\subsection{Welfare expectancy}

Life expectancy from birth $\left(e_{0}\right)$ represents the expected value of lifespan, with the "value" of each possible lifespan being equal to its length, each additional year of life being weighed the same. Calculations of generation time - the expected age of mothers - follow a similar formula but allow ages to differ in value as age-specific fecundity varies. Welfare may similarly vary with age, as juveniles, sub-adults, reproductive adults and senescent animals face different levels 
and forms of disease, competition, predation and environmental hardship. This potential for variation calls for a distinct concept of welfare expectancy.

Welfare expectancy from birth $\left(W_{0}\right)$ is calculated by summing the age-specific welfare values experienced over the ages encompassed by each possible lifespan, and then taking the mean weighted by the probability of each lifespan: $W_{0}=\sum_{x=0}^{\omega}\left(d_{x} \times w_{x}\right) \ldots$ where $d_{x}=$ probability from birth of dying at age $x ; w_{x}=$ net total welfare experienced during a lifespan of $x$ years; $\omega=$ maximum lifespan. For example, the expected value of a 5 -year life would be equal to the total amount of welfare experienced between ages 0 and 5 , multiplied by the probability of a 5-year lifespan. Repeating this operation for each possible lifespan and taking the sum would yield the welfare expectancy for a typical individual born into the population in question.

A relative welfare expectancy (RWE) index can also be calculated using values of $w_{x}$ normalized around one $\left(w_{x}=\left(w_{x} \cdot \omega\right) / \sum_{x=0}^{\omega} w_{x}\right)$ to calculate welfare expectancy $\left(W_{0, R}\right)$, and then dividing welfare expectancy by life expectancy: $\mathrm{RWE}=W_{0, R} / e_{0}$. This index expresses the variability of lifespan in relation to periods of high or low welfare. An RWE $>1$ implies that most individuals will survive to experience periods of life characterized by above-average welfare, while for RWE $<1$, a population's survivorship patterns mean that most individuals will only experience below-average periods of life. For RWE $>1$, welfare can be said to be 'outperforming' life expectancy, as the average instantaneous welfare value during the lifetime of a typical individual would be greater than for an individual who lived out their theoretical maximum lifespan. In general, either high early-life survivorship/welfare (many individuals experiencing the best years) or extremely low late-life survivorship/welfare (few individuals experiencing the worst years) can yield a high RWE index. As life expectancy approaches the maximum lifespan of a species, RWE will tend towards 1 because the average welfare an individual experiences in their lifetime is increasingly representative of the welfare distribution over their species' maximum lifespan.

\subsection{Welfare elasticity analysis}

An elasticity analysis was also applied to each population to see whether they differed in the age at which a proportional reduction in mortality rate would have the greatest impact on individual's lifetime welfare expectancy. The elasticity of welfare expectancy to each age's survival rate was scored as the product of 1 ) the survivorship up to that age $\left.\left(I_{x}\right), 2\right)$ the mortality rate at that age $\left(m_{x}\right)$, and 3 ) the remaining welfare expectancy conditional on surviving that age $\left(W_{x}\right)$. The age with the highest elasticity score was considered the welfare 'bottleneck' age for individuals of that population.

\subsection{Illustrating the welfare expectancy approach}

To provide an initial illustration of the approach described here using as detailed and explicit a case as possible, a Leslie matrix was generated from age-specific rates of survival and welfare (life satisfaction) among the human population of the United Kingdom, using published statistics from the UK Office for National Statistics (ONS, 2016; 2019). This population was subjected to the welfare expectancy analyses described above. It is so far unique in having empirically determined age-specific welfare values, as well as vital rates calculated from known fates of 
thousands of individuals, permitting the clearest possible illustration of the welfare expectancy approach.
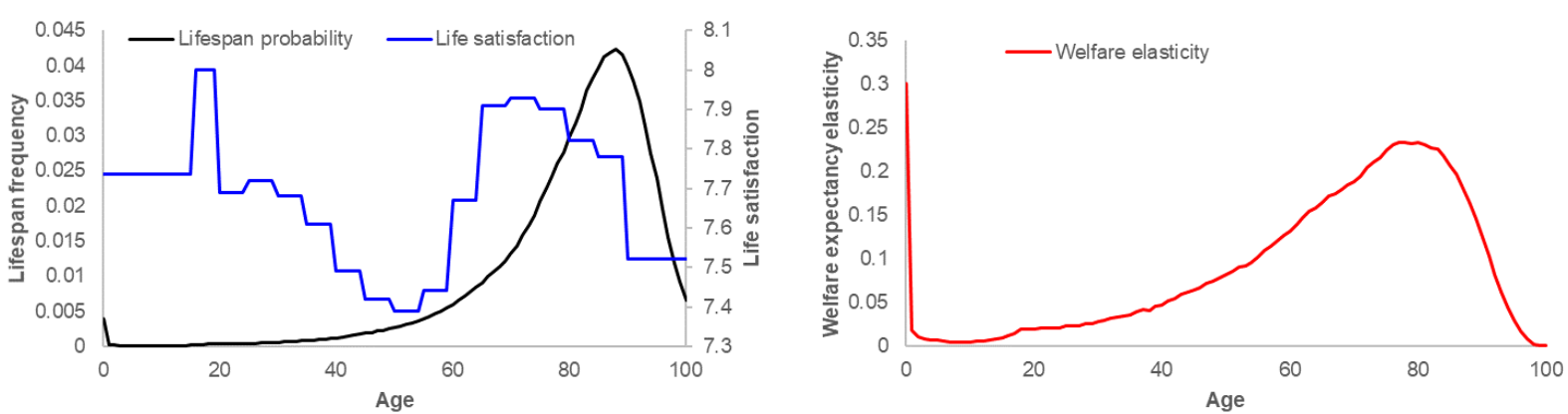

Figure 1: (Left) The lifespan distribution of UK humans plotted against age-specific welfare (life satisfaction). Most individuals die old enough to experience both highs and lows of welfare coinciding with important life transitions. (Right) Elasticity of welfare expectancy to marginal reduction in age-specific mortality rate.

The UK human lifespan distribution begins with a modest spike representing infant mortality. It then abruptly falls after the first year, rising again gradually from throughout senescent life before spiking at 88 (Figure 1). The life expectancy at birth was approximately 80 years. Welfare (life satisfaction) is bimodal, with peaks in the early-twenties (beginning of independent life) and mid-sixties (beginning of retirement) and troughs in the mid-forties and old age. The population's RWE index was 1.00 , as the vast majority of individuals lived to old age and experienced periods of high and low welfare in roughly equal measure (Figure 1, left). The age at which welfare expectancy was most elastic to a marginal reduction in mortality was during year 1 , combating low but non-trivial infant mortality (Figure 1, right). This is to be expected given that all individuals are alive and able to benefit from interventions at this age, and individuals surviving infanthood may expect a long and happy life. Notably, age 80 has only slightly lower elasticity. This is because, although welfare expectancy from age 80 onward is much lower than welfare expectancy from birth, the population's extremely high survival rates up to old age mean that $\sim 60 \%$ of individuals survive to benefit from interventions at age 80 . Moreover, because the age-specific mortality rate is much higher than during infanthood, any intervention may have a proportionally greater effect.

\subsection{Modelling age-specific welfare}

The distribution of welfare with respect to age is a crucial determinant of how changes in demographic vital rates affect individual welfare expectancy, but there is yet virtually no direct evidence on the age-specific welfare of wild animals. However, to explore the implications of varying age-specific welfare, I assumed that welfare at a given age was proportional to the probability of surviving that year of life. It must be stressed that this is a working hypothesis, adopted for the purpose of illustrating the effects of age-dependent welfare under various real- 
life demographies. The assumption remains to be tested, but its rationale, implications and alternatives will be discussed later. Welfare expectancy specifically calculated under this assumption will be denoted as $W_{0, s}$.

\subsection{Data obtention}

Published MPMs were obtained from the COMADRE database, which serves as a curated repository for matrix population models (Salguero-Gomez et al., 2016). A subset of 152 population matrices, representing 88 species, were selected according to the following criteria, in the form of variables defined in the COMADRE documentation: MatrixComposite == "Mean" \& MatrixTreatment $==$ 'Unmanipulated' \& MatrixCaptivity $==$ 'W' \& MatrixSplit $==$ "Divided" \& ProjectionInterval $==1$ \& MatrixCriteriaOntogeny $==$ 'No' \& MatrixCriteriaSize $==$ 'No' \& MatrixCriteriaAge == 'Yes'. Only the survival matrices (\$matU) were used. From this subset, matrices were discarded if they had missing data ("NA" values), stage-specific transition probabilities summing to $>1$ or to 0 at non-terminal stages or were duplicates. All MPMs were annual Leslie or Leslie+ matrices (Carslake et al., 2009). Original credit for these matrices goes to their respective authors, as attributed in the COMADRE database.

Four major taxonomic classes were represented among the population matrices drawn from COMADRE: Actinopterygii (ray-finned fishes), Aves (birds), Mammalia (mammals), and Reptilia (reptiles). These were represented by $16,54,72$, and 10 populations, respectively. Maximum lifespans for each species was obtained from the AnAge database (De Magalhães et al., 2005), if available, or else imputed as the average of represented congeners or family relatives. In the case of Leslie matrices, the maximum lifespan was determined by the dimension of the matrix itself. Statistics for each of these matrices can be found in appendix Table A1.

\section{Results}

\subsection{Life expectancy}

The mean life expectancy across the wild animal population models obtained from COMADRE was calculated at 4.39 years, or a median of 3.14 years. Approximately $16 \%$ of populations had life expectancies of $<1$ year, and $74 \%$ had life expectancies of $<5$ years. As a proportion of maximum lifespan, the average life expectancy was $16 \%$, with only $5 \%$ of populations having life expectancies $>33 \%$ of their maximum. Mammal populations had the highest average life expectancy (6.8 years), followed by birds (2.8 years) and reptiles (2.0 years). The ray-finned fish had the lowest average life expectancy, at 0.6 years (Figure 2). 
30

25

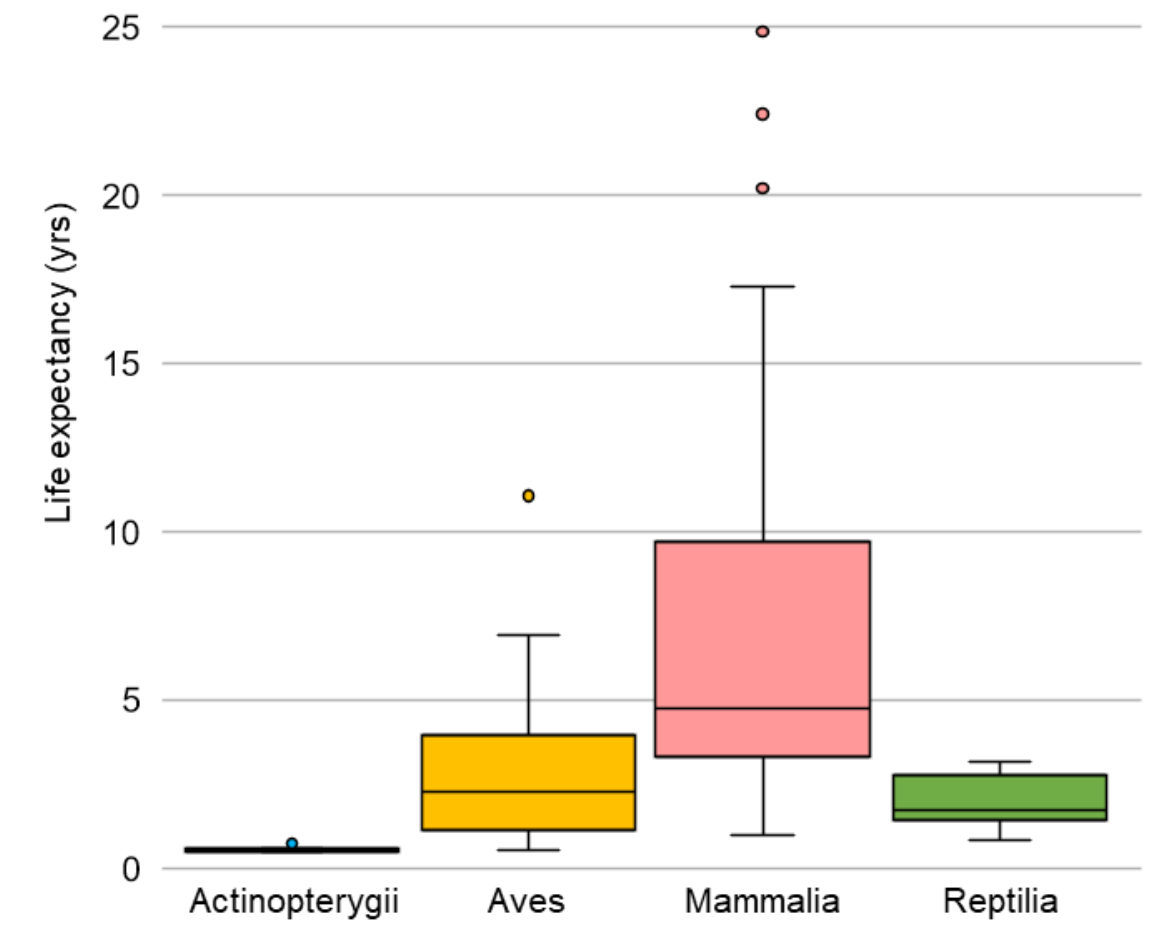

Figure 2: Box and whiskers plot of life expectancy by taxonomic class. Populations were used as data points.

\subsection{Welfare expectancy}

The mean RWE index was 0.87 , median 0.97 . Only $10 \%$ of populations had relative welfare expectancies of $>1.1$, while $33 \%$ scored $<0.9$. Mammal and bird populations had RWE values typically near 1 (Figure 3). Mammalia had a tighter distribution around 1, consistent with the longer life expectancies of mammalian populations, but with positive and negative outliers. Actinopterygii had by far the lowest mean RWE (0.20). Reptilian RWE values were intermediate, though all below 1 except for an extreme positive outlier (RWE=2.38) based on data from a 


\section{5}

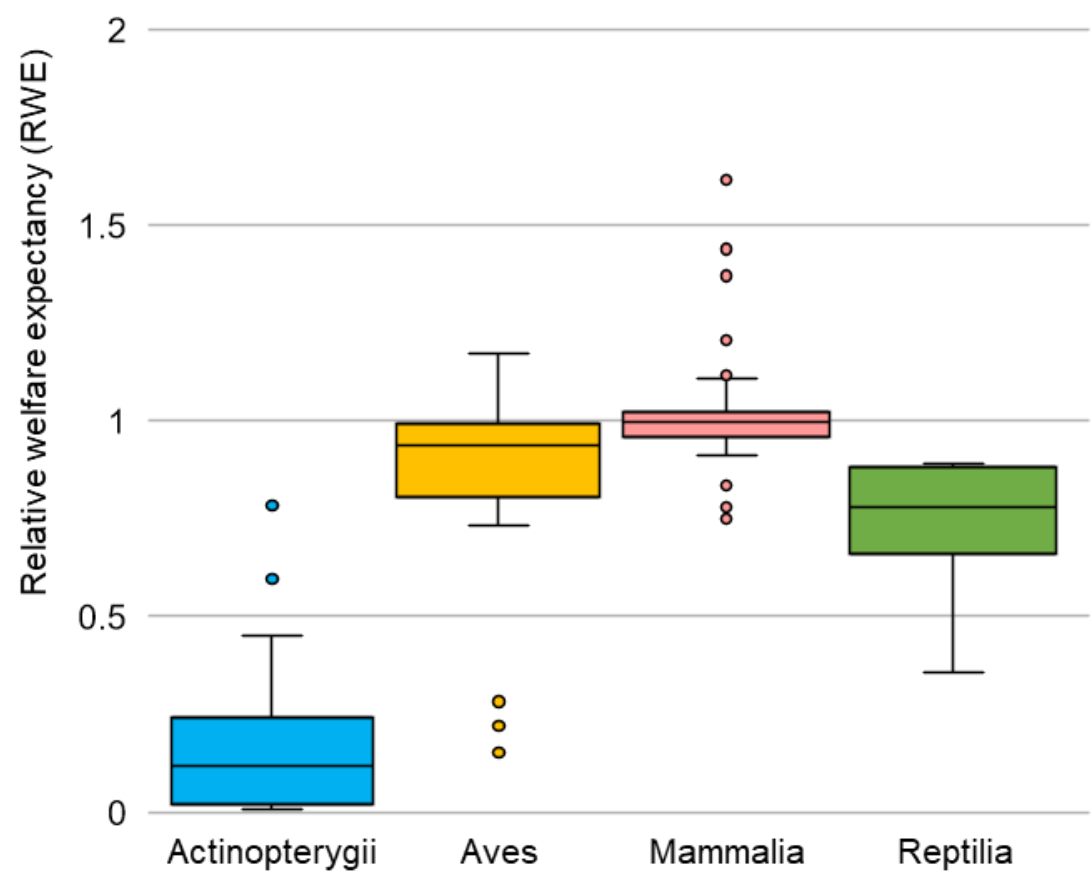

Figure 3: Box and whiskers plot of RWE by taxonomic class, using populations as data points. The high-RWE outlier among Reptilia is a population of painted turtles (Chrysemys picta).

The average annual survival distributions of all populations with low (first quartile) and high (third quartile) RWE were plotted and found to cover distinct value ranges only during early life. High-RWE populations sustained a relatively high survival rate from birth onwards. Meanwhile, low-RWE populations had extremely low first-year survival rates, yet many attained higher survival rates similar to those of high-RWE populations by age 6 (Figure 4). 


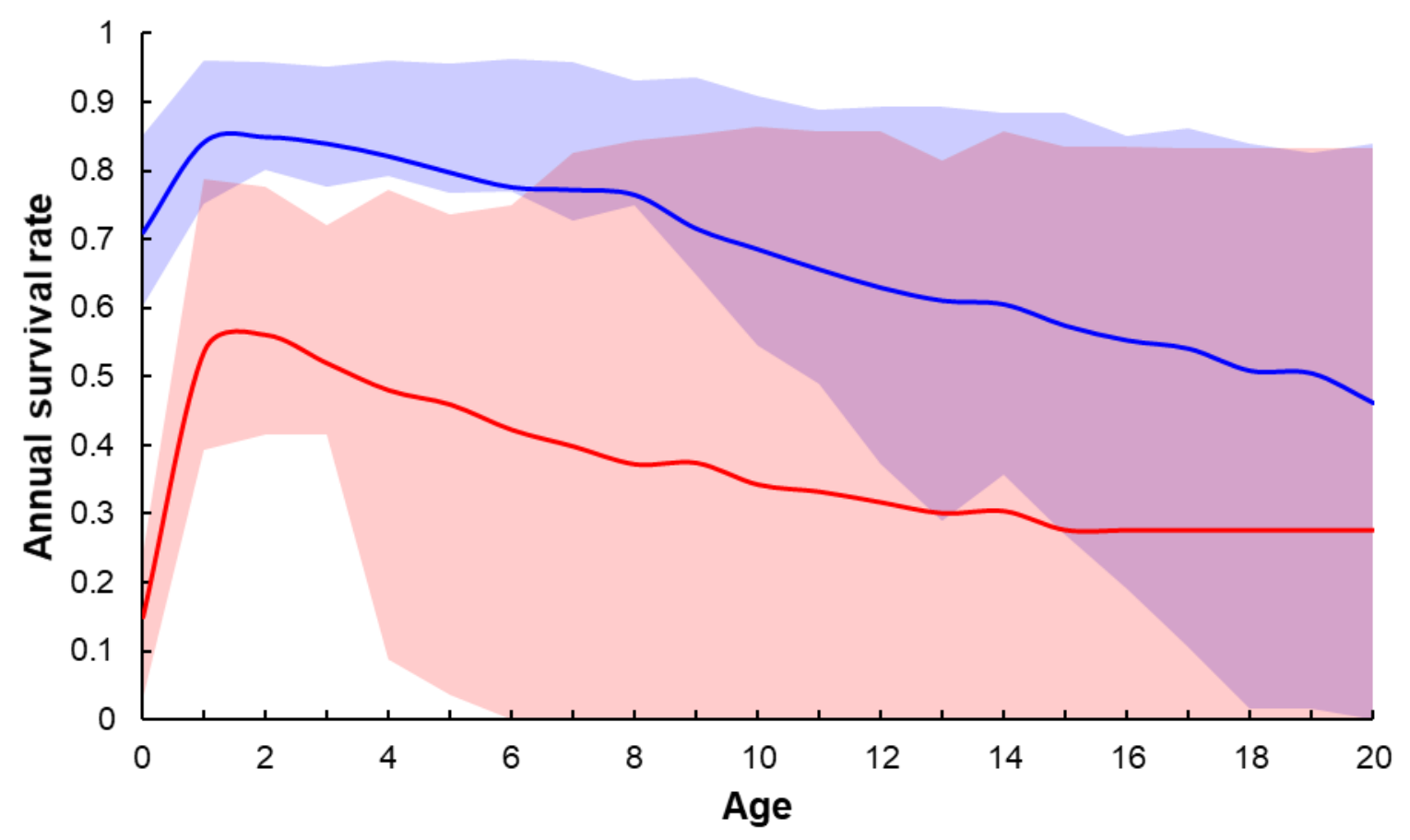

Figure 4: Mean age-specific annual survival rates for high-RWE populations (top 25\%; blue line) and low-RWE populations (bottom 25\%; red line). Lighter blue and red bands cover the interquartile ranges about each mean line. The purple area depicts overlapping age-specific survival distributions of the high- and low-RWE groups.

\subsection{Age-specific elasticity of welfare expectancy}

The elasticity analysis identified only nine populations for which an infinitesimal reduction in mortality rate after age 0 would lead to a greater increase in welfare expectancy than an equivalent reduction in first-year mortality. For five of these populations, the age of highest welfare elasticity was year 1 or 2 , enabled by high survivorship over the preceding period followed by a drop (the 'bottleneck'). The other four bottlenecked populations belong to the same species, Capra ibex, and show a distinct lifespan distribution that leads to peak welfare elasticity around age 7 or 12 . In both cases, the elasticity of welfare expectancy to an agespecific reduction in mortality parallels the lifespan distribution (Figure 5). 
250

251

252

253

254

255

256

257

258

259

260

261

262

263

264

265

266

267

268

269

270

271

272

273

274

275

276

277

278

279

280

281

282

283

284
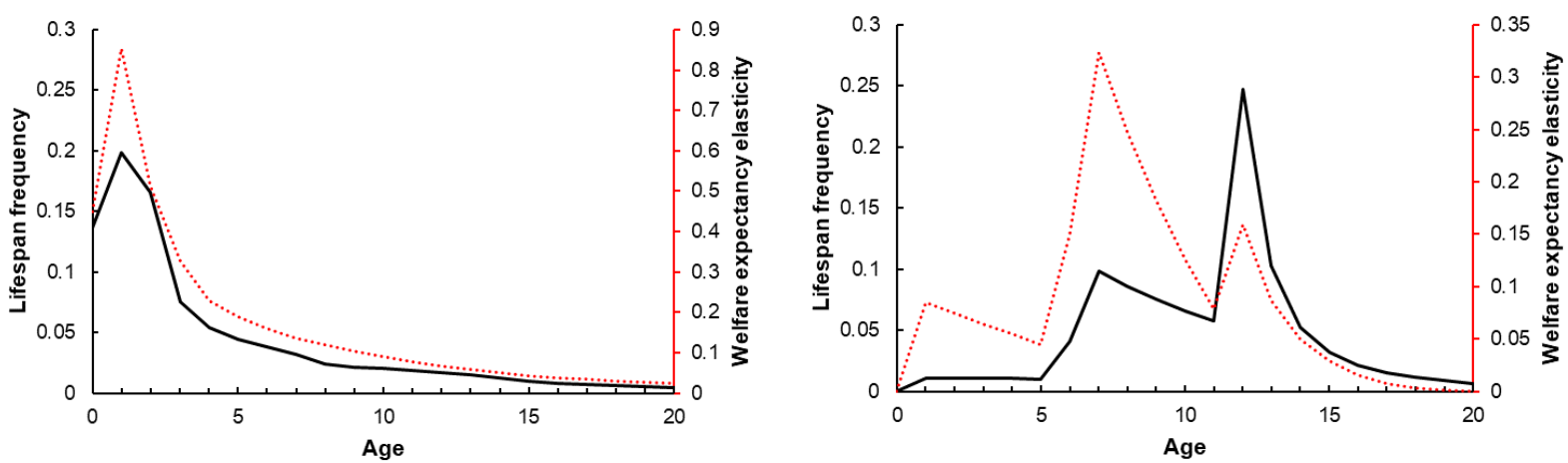

Figure 5: The lifespan distribution (solid black line) and corresponding age-specific welfare elasticity (dotted red line) of five 'bottlenecked' populations with low age 0-1 survival but higher age 1-2 and 2-3 survival (left) and four Capra ibex populations where welfare elasticity peaked around age 7 or 12 (right).

\section{Discussion}

\subsection{Life expectancy}

Most of the individuals observable at any given time in many wild animal populations are the lucky ones who have survived the challenges characteristic of early life. Among the populations considered here, based on published demographic models, the typical life expectancy is merely $14 \%$ of the theoretical lifespan. While this is the median across populations, given that predominantly shorter-lived taxa, such as the ray-finned fish, may produce far more offspring per generation than longer-lived ones, the average life expectancy across individuals is likely to be much smaller. The criterion of annual periodicity used for selecting population matrices from COMADRE could further bias life expectancy upward, since an annual time-step would provide poor resolution when studying a very short-lived animal. This is particularly relevant for considering the lifespans of juveniles, which may encompass a fraction of one year.

Not all newborns of a given population will have the same individual life expectancies, after the predictive power of parental phenotypes and circumstances of birth are taken into account. Parental age, maternal body mass, clutch size, and relative timing of birth have often been found to predict lifespan (e.g. Reid et al., 2010; Einum and Fleming, 2000; Tamada and Iwata, 2005; Ronget et al., 2018). Field research developing such predictors of individual differences could help define life expectancy more precisely for subsets of a population, helping to target interventions on the most vulnerable animals.

\subsection{Age-specific welfare}

Variation in lifespan also magnifies the relevance of differences in average quality of life with respect to age among a given population. In a comparison of two populations with the same life expectancy and theoretical lifespan, the one in which the largest proportion of individuals survive to experience the most pleasant years of life available to them will have a greater potential for net-positive welfare. 
In the present analyses, I assumed that the welfare experienced at a particular age was proportional to the probability of surviving that year of life. This is a plausible working hypothesis since the same factors that lead to mortality (e.g. disease, vulnerability to predators, competition for food) have been shown to lead to chronic stress and poor physical condition (Clinchy et al., 2013; Bateson et al., 2015). Assuming this model of age-specific welfare, and equal life expectancies, populations with a) very low mortality in early life followed by high mortality later in life would achieve higher welfare than populations with b) a constant rate of mortality, and these would in turn achieve higher welfare than c) populations with high early-life mortality but high adult survivorship. These scenarios roughly correspond to the survivorship curve typology of Demetrius (1978).

A number of alternative hypotheses might also describe the relationship between welfare and age. For example, welfare might peak around the same age as peak reproduction. This could occur due to hormonal factors, or simply because natural selection tends to optimize fitness around reproduction, and body condition is likely related to welfare; though this might be perturbed by intense juvenile competition or the need to provide protection for offspring, which could drive peak physical fitness earlier or later than peak fecundity. On the other hand, reproductive age might bring on poor welfare, especially in species with intense sexual competition (e.g. Clinton and Le Boeuf, 1993). Either of these reproductive age-centric hypotheses would likely still predict a correlation between survival and welfare, given the interaction of age-specific mortality and reproductive timing in directing the evolution of life history strategies (Charlesworth, 1980).

It is also conceivable that the determinants of welfare are so complex that welfare varies irregularly over a lifetime, or average welfare might even be invariant with age in some animals. If welfare is invariant with age, welfare expectancy will scale linearly with life expectancy. However, it seems highly likely that welfare would shift in some direction concurrent with major life history transitions, like the maturation of a tadpole or caterpillar, or sexual maturation in most species, especially when this is accompanied by changes in environment, such as with the ejection of young male hyenas or female meerkats from their natal groups (Maag et al., 2019).

Previous reviews have recognized the need to integrate welfare experienced over the lifetime of domestic animals (e.g. FAWC, 2009; Pickard, 2013). The concept of welfare expectancy developed here applies this to wild animal populations, using the principle of expected value to account for their inherent variability. Recently, Bateson and Poirier (2019) proposed that the ratio between biological and chronological age could be used as a proxy for lifetime welfare. The premise of this approach is that somatic damage and repair, which determine biological age, often result from physiological processes that are associated with affective states, such as stress or happiness. Indeed, adverse conditions such as sibling competition have been shown to lead to accelerated biological aging limited to the study period, especially when the individual is a weaker competitor (Gott et al., 2018). Surveying population-level variation or tracking individual longitudinal variation in the biological-to-chronological age ratio, through measurements such as telomere length, could be a cost-effective way to estimate relative age- 
specific welfare within wild populations. In the Anthropocene, a large proportion of wild animal stress may be caused by human activity, and so biomarkers such as these could provide evidence of habitat quality from the perspective of the animals themselves and serve as additional holistic evidence to present policymakers (Wikelski and Cooke, 2006).

\subsection{Welfare expectancy} Since only living animals are capable of experiencing any level of welfare, life expectancy has profound implications for the net welfare of a population. I have defined welfare expectancy from the perspective of an individual being born into a population and facing an uncertain lifespan. Welfare expectancy revolves around age-specific variation in welfare and the implication that some lifespans will encompass a greater quality and quantity of welfare than others. Many animals die as juveniles, only experiencing the level of welfare associated with that stage of life as a member of their species; others survive to adulthood but fail to reproduce, while others live long, iteroparous lives.

The potential for age-specific variation in average welfare suggests that welfare expectancy may 'outperform' life expectancy in populations where welfare is highest in early life, which most individuals will live to experience. Conversely, in populations where juvenile welfare is lower than adult welfare, welfare expectancy may 'underperform' life expectancy because most individuals never see their best years. This notion drives the concept of relative welfare expectancy (RWE). Assuming the correlation between age-specific survival and welfare argued above, welfare expectancy in one third of the populations considered here underperformed their life expectancy by at least $10 \%$ (RWE < 0.9), while only eight percent outperformed life expectancy to the same degree (RWE > 1.1). Importantly, this conclusion was neither inevitable nor universal. For example, in the study of $C$. ibex referenced earlier, not a single tagged animal was found to have died during their first year (Toïgo et al., 2007). In contrast, the chinook salmon (Oncorhynchus tshawytscha) had a first-year mortality rate of $\sim 94 \%$ despite a theoretical lifespan of nine years attained by a tiny proportion of individuals (Wilson, 2003). Unfortunately, this second pattern appears to be more common, and is likely to be more common in nature after taxon-related publication bias and differences in fecundity are taken into account.

It should also be noted that RWE itself merely describes the natural state of a population. It can inform population management as a descriptive statistic for prioritizing aid to particular demographics within a population, as a low RWE indicates that something about the population's age-specific survival pattern is out of order. However, the metric should not necessarily be maximized by any possible means; for example, higher RWE could sometimes be achieved by reducing late-life welfare as opposed to increasing early-life survival. Welfare expectancy itself, which underlies RWE, should be maximized through population management. However, the average welfare expectancy of individuals may need to be traded off against the size of a population, as increasing density has potential to reduce both survivorship and welfare.

\subsection{Welfare elasticity}


A corollary of thinking about lifetime welfare in terms of expected value is the possibility of 'bottleneck' ages: ages where survival rate abruptly falls, which are preceded by high survivorship and followed by positive welfare expectancy. This concept is analogous to demographic elasticity, which is analyzed to identify which life stages and vital rates exercise the most control over a population's marginal net reproductive rate (Benton and Grant, 1999). Whereas age-specific demographic elasticity depends on the parallel dynamics of survival and fecundity, welfare elasticity depends on an age's relation to patterns of survivorship and welfare. In general, the value of increasing survival rate at a particular age depends on the proportion of individuals in the cohort surviving to reach that age and their expectation of future welfare.

Bottlenecks occurring relatively early in life, when a respectable proportion of individuals remain alive, may be promising objects for wildlife interventions from both a conservation perspective accounting for both biodiversity and welfare (Carslake et al., 2009). However, because of how few individuals of most species survive to adulthood, the conditions for a mid-life bottleneck period to be the most sensitive target for intervention appear to be uncommon. Thus, conservation interventions justified on holistic welfare grounds are likely to be most efficient when they target younger animals, who will generally be more numerous. Calculations of the expected value of any welfare intervention should account for the ages of individuals who would be affected by the intervention.

A more precise understanding of these survival and welfare parameters could elaborate on welfare expectancy through related statistical concepts, such as welfare skewness and variability (c.f. Caswell 2009 for life expectancy). Variance in welfare would be particularly important to understand if we prioritize solving cases of extremely poor welfare. If intraspecific variation in welfare is structured by geography, phenology or phylogeny, it might also be appropriate to study and manage the welfare of those groups separately, similar to how demographically independent units are often managed separately for biodiversity conservation (e.g. Höglund et al., 2011).

\subsection{Death as a discrete welfare event}

Previous publications have reasoned that for an individual animal to have had a 'life worth living', they must have experienced enough pleasure during their life to compensate for a potentially painful death (e.g. FAWC, 2009; Scherer et al., 2018). For animals who are able to live out most of their full lifespans, this seems highly plausible; but for the vast majority of animals, who experience only a small fraction of their potential lives, far more research into the causes and their experiences of death is needed to understand the valence of their lives.

Cause of death, and therefore the duration and pain of an animal's experience of dying, may also vary with age similarly to welfare, though probably less systematically. In a hypothetical species, juveniles might be most likely to starve while adults are most likely to be predated, with the relative probabilities of these and other mortality factors shifting over a lifetime. If future research suggests that the pain of death is a sufficiently strong factor to negate some of the positive welfare an animal might have experienced while alive, age-specific variation in the incidence of various manners of death and their severity would also be important to account for. 
It is already possible to assess the welfare state of an individual - and to compare individuals within a species - using physiological and behavioral indicators. Several studies have documented consistent differences in stress hormone levels associated with different causes of death, supporting the intuitive hypothesis that some involve greater suffering than others. For example, stranded whales showed dramatically higher fecal glucocorticoid (fGC) concentrations than fishing gear-entangled whales, whose fGC concentrations were in turn dramatically higher than those of whales killed quickly by a vessel strike (Rolland et al., 2017). Similarly, deer who were shot with a rifle showed lower cortisol levels than those hunted by dogs (Bradshaw and Bateson, 2000).

\section{6 $\underline{\text { Conclusions and implications }}$}

The consideration of age structure when evaluating the overall state of welfare in a wild animal population brings several general implications and heuristics. 1) Most individuals live only a tiny proportion of their potential lifespans, so the welfare of healthy adults, who tend to be most visible, is not representative. 2) As a consequence of this, interventions to improve welfare can normally achieve greatest impact by focusing on the youngest animals. 3) Welfare and manner of death are likely to vary with age, potentially disrupting or augmenting the focus on the youngest animals. The ideal welfare scenario - within a fixed theoretical lifespan - is for as large a proportion of animals as possible to live through the most pleasant years of life and die at the age where the typical manner of death is the quickest and least painful. 4) Since only living animals experience any welfare at all, life expectancy is a crucial factor in determining the scope for positive or negative welfare. However, if welfare varies with age, the typical individual may experience higher (or lower) net welfare than their relative life expectancy would suggest.

At the individual level, welfare expectancy unites two distinct concepts: the day-to-day quality of welfare and quantity of welfare experienced over an individual's lifetime. However, a similar quantity-quality distinction applies at the level of populations, with welfare expectancy addressing the quality side of the argument and quantity being determined by the population size. Management decisions should be based on the sum of welfare expectancy, but density dependence of age-specific survival rates will in many cases lead to a trade-off between the average and the sum of welfare expectancy in a population (assuming habitats do not grow), implying the existence of an optimum density (e.g. Cubaynes et al., 2014). Understanding the relative sensitivities of a specific population's vital rates to density is therefore crucial for optimal welfare-centric management.

Once better data on age-specific welfare become available, the welfare expectancy framework could also help wildlife managers to identity specific ages or stages to target for population control where a reduction in survival rate would lead to the smallest possible change in welfare expectancy for the largest possible reduction in net reproductive rate. Such compromises could also be identified for growth-oriented population management, ideally achieving high individual welfare among a large population. 
The field of welfare biology is at a very early stage, having received little dedicated work from the life sciences until recently. While progress is still limited by the lack of empirical studies of wild animal welfare, it is hoped that this theoretical work, drawing on some of the same published demographic data which are widely used for informing biodiversity conservation, will help establish a paradigm for prioritizing and interpreting future research in welfare biology.

\section{References}

1. Bateson, M., Emmerson, M., Ergün, G., Monaghan, P., \& Nettle, D. (2015). Opposite effects of early-life competition and developmental telomere attrition on cognitive biases in juvenile European starlings. PLoS One, 10(7), e0132602.

2. Bateson, M., \& Poirier, C. (2019). Can biomarkers of biological age be used to assess cumulative lifetime experience? Animal Welfare, 28(1), 41-56.

3. Beausoleil, N. J., Mellor, D. J., Baker, L., Baker, S. E., Bellio, M., Clarke, A. S., ... \& Pitcher, B. J. (2018). 'Feelings and Fitness' not 'Feelings or Fitness'-the raison d'être of Conservation Welfare, which aligns conservation and animal welfare objectives. Frontiers in Veterinary Science, 5, 296.

4. Benton, T. G., \& Grant, A. (1999). Elasticity analysis as an important tool in evolutionary and population ecology. Trends in Ecology \& Evolution, 14(12), 467-471.

5. Bradshaw, E. L., \& Bateson, P. (2000). Welfare implications of culling red deer (Cervus elaphus). Animal Welfare, 9(1), 3-24.

6. Carey, J. R. (2001). Insect biodemography. Annual Review of Entomology, 46(1), 79-110.

7. Caswell, H. (2001). Matrix Population Models: Construction, Analysis, and Interpretation. 2nd edn Sinauer Associates. Inc., Sunderland, MA.

8. Carslake, D., Townley, S., \& Hodgson, D. J. (2009). Patterns and rules for sensitivity and elasticity in population projection matrices. Ecology, 90(11), 3258-3267.

9. Charlesworth, B. 1980. Evolution in age structured populations. Cambridge University Press, Cambridge, UK.

10. Clinchy, M., Sheriff, M. J., \& Zanette, L. Y. (2013). Predator-induced stress and the ecology of fear. Functional Ecology, 27(1), 56-65.

11. Clinton, W. L., \& Le Boeuf, B. J. (1993). Sexual selection's effects on male life history and the pattern of male mortality. Ecology, 74(6), 1884-1892.

12. Cubaynes, S., MacNulty, D. R., Stahler, D. R., Quimby, K. A., Smith, D. W., \& Coulson, T. (2014). Density-dependent intraspecific aggression regulates survival in northern Yellowstone wolves (Canis lupus). Journal of Animal Ecology, 83(6), 1344-1356.

13. De Magalhães, J. P., Costa, J., \& Toussaint, O. (2005). HAGR: the human ageing genomic resources. Nucleic Acids Research, 33, D537-D543.

14. Demetrius, L. (1978). Adaptive value, entropy and survivorship curves. Nature, 275(5677), 213.

15. Dillon, K. G., \& Conway, C. J. (2018). Nest predation risk explains variation in avian clutch size. Behavioral Ecology, 29(2), 301-311.

16. Einum, S., \& Fleming, I. A. (2000). Highly fecund mothers sacrifice offspring survival to maximize fitness. Nature, 405(6786), 565.

17. Farm Animal Welfare Council (FAWC) 2009 Farm Animal Welfare in Great Britain: Past, Present and Future. FAWC: London, UK 
18. Gadgil, M., \& Bossert, W. H. (1970). Life historical consequences of natural selection. The American Naturalist, 104(935), 1-24.

19. Gott, A., Andrews, C., Hormigos, M. L., Spencer, K., Bateson, M., \& Nettle, D. (2018). Chronological age, biological age, and individual variation in the stress response in the European starling: a follow-up study. PeerJ, 6, e5842.

20. Heppell, S. S., Caswell, H., \& Crowder, L. B. (2000). Life histories and elasticity patterns: perturbation analysis for species with minimal demographic data. Ecology, 81(3), 654-665.

21. Höglund, J., Larsson, J. K., Corrales, C., Santafé, G., Baines, D., \& Segelbacher, G. (2011). Genetic structure among black grouse in Britain: implications for designing conservation units. Animal Conservation, 14(4), 400-408.

22. Johnston, S. E., Gratten, J., Berenos, C., Pilkington, J. G., Clutton-Brock, T. H., Pemberton, J. M., \& Slate, J. (2013). Life history trade-offs at a single locus maintain sexually selected genetic variation. Nature, 502(7469), 93.

23. Maag, N., Cozzi, G., Bateman, A., Heistermann, M., Ganswindt, A., Manser, M., ... \& Ozgul, A. (2019). Cost of dispersal in a social mammal: body mass loss and increased stress. Proceedings of the Royal Society B, 286(1896), 20190033.

24. Ng, Y. K. (1995). Towards welfare biology: Evolutionary economics of animal consciousness and suffering. Biology and Philosophy, 10(3), 255-285.

25. Office for National Statistics. (2019). National Life Tables, UK: 2016 to 2018. Retrieved from https://www.ons.gov.uk/peoplepopulationandcommunity/birthsdeathsandmarriages/lifeexpectanci es/bulletins/nationallifetablesunitedkingdom/2016to2018.

26. Office for National Statistics. (2016). Headline estimates of personal well-being from the Annual Population Survey (APS): by selected geographies and personal characteristics, April 2015 to March 2016. Retrieved from https://www.ons.gov.uk/file?uri=/peoplepopulationandcommunity/wellbeing/datasets/headlineesti matesofpersonalwellbeing/april2015tomarch2016selectedgeographiesandpersonalcharacteristics/ headlineestimatesofpersonalwellbeing2015to201621.xls.

27. Pettorelli, N., \& Durant, S. M. (2007). Family effects on early survival and variance in long-term reproductive success of female cheetahs. Journal of Animal Ecology, 76(5), 908-914.

28. Pickard, J., Buchanan-Smith, H. M., Dennis, M., Flecknell, P., Joannides, A., Lemon, R., ... \& Schultz, W. (2013). Review of the assessment of cumulative severity and lifetime experience in non-human primates used in neuroscience research. London: Animal Procedures Committee.

29. Reid, J. M., Bignal, E. M., Bignal, S., McCracken, D. I., Bogdanova, M. I., \& Monaghan, P. (2010). Parent age, lifespan and offspring survival: structured variation in life history in a wild population. Journal of Animal Ecology, 79(4), 851-862.

30. Rolland, R. M., McLellan, W. A., Moore, M. J., Harms, C. A., Burgess, E. A., \& Hunt, K. E. (2017). Fecal glucocorticoids and anthropogenic injury and mortality in North Atlantic right whales Eubalaena glacialis. Endangered Species Research, 34, 417-429.

31. Ronget, V., Gaillard, J. M., Coulson, T., Garratt, M., Gueyffier, F., Lega, J. C., \& Lemaître, J. F. (2018). Causes and consequences of variation in offspring body mass: meta-analyses in birds and mammals. Biological Reviews, 93(1), 1-27.

32. Salguero-Gómez, R., Jones, O. R., Archer, C. R., Bein, C., de Buhr, H., Farack, C., ... \& Römer, G. (2016). COMADRE: a global data base of animal demography. Journal of Animal Ecology, 85(2), 371-384.

33. Scherer, L., Tomasik, B., Rueda, O., \& Pfister, S. (2018). Framework for integrating animal welfare into life cycle sustainability assessment. The International Journal of Life Cycle Assessment, 23(7), 1476-1490.

34. Schwarzenberger, F. (2007). The many uses of non-invasive faecal steroid monitoring in zoo and wildlife species. International Zoo Yearbook, 41(1), 52-74. 
35. Sol, D., Maspons, J., Gonzalez-Voyer, A., Morales-Castilla, I., Garamszegi, L. Z., \& Møller, A. P. (2018). Risk-taking behavior, urbanization and the pace of life in birds. Behavioral Ecology and Sociobiology, 72(3), 59.

36. Tamada, K., \& Iwata, K. (2005). Intra-specific variations of egg size, clutch size and larval survival related to maternal size in amphidromous Rhinogobius goby. Environmental Biology of Fishes, 559 73(4), 379-389.

37. Tinkle, D. W., Congdon, J. D., \& Rosen, P. C. (1981). Nesting frequency and success: implications for the demography of painted turtles. Ecology, 62(6), 1426-1432.

38. Toïgo, C., Gaillard, J. M., Festa-Bianchet, M, Largo, E., Michallet, J., \& Maillard, D. (2007). Sexand age-specific survival of the highly dimorphic Alpine ibex: evidence for a conservative lifehistory tactic. Journal of Animal Ecology, 76(4), 679-686.

39. Wikelski, M., \& Cooke, S. J. (2006). Conservation physiology. Trends in Ecology \& Evolution, 21(1), 38-46.

40. Wilson, P. H. (2003). Using population projection matrices to evaluate recovery strategies for Snake River spring and summer Chinook salmon. Conservation Biology, 17(3), 782-794. 


\section{Appendix}

604

605

Table A1: Core numerical results for each population from COMADRE included in the analysis.

606

\begin{tabular}{|c|c|c|c|c|c|}
\hline Class & Genus species & $\begin{array}{c}\text { Max } \\
\text { lifespan }\end{array}$ & $\begin{array}{c}\text { Life } \\
\text { expectancy }\end{array}$ & $W_{0, s}$ & RWE \\
\hline Actinopterygii & Ammocrypta pellucida & 3 & 0.52 & 0.02 & 0.14 \\
\hline Actinopterygii & Astroblepus ubidiai & 6 & 0.79 & 0.20 & 0.78 \\
\hline Actinopterygii & Cottus sp. & 5.89 & 0.52 & 0.01 & 0.07 \\
\hline Actinopterygii & Erimyzon sucetta & 6 & 0.50 & 0.00 & 0.01 \\
\hline Actinopterygii & Hybognathus argyritis & 4.4 & 0.51 & 0.01 & 0.07 \\
\hline Actinopterygii & Notropis percobromus & 3.38 & 0.50 & 0.00 & 0.04 \\
\hline Actinopterygii & Notropis photogenis & 3.38 & 0.50 & 0.00 & 0.01 \\
\hline Actinopterygii & Notropis photogenis & 3.38 & 0.50 & 0.00 & 0.01 \\
\hline Actinopterygii & Oncorhynchus tshawytscha & 9 & 0.56 & 0.08 & 0.24 \\
\hline Actinopterygii & Oncorhynchus tshawytscha & 9 & 0.56 & 0.08 & 0.24 \\
\hline Actinopterygii & Oncorhynchus tshawytscha & 9 & 0.56 & 0.08 & 0.24 \\
\hline Actinopterygii & Opsopoeodus emiliae & 4.4 & 0.51 & 0.01 & 0.09 \\
\hline Actinopterygii & Pimephales promelas & 2 & 0.50 & 0.00 & 0.01 \\
\hline Actinopterygii & Zoarces viviparus & 10 & 0.55 & 0.04 & 0.14 \\
\hline Actinopterygii & Zoarces viviparus & 10 & 0.81 & 0.22 & 0.60 \\
\hline Actinopterygii & Zoarces viviparus & 10 & 0.72 & 0.16 & 0.45 \\
\hline Aves & Anas laysanensis & 12 & 3.17 & 2.80 & 0.99 \\
\hline Aves & Anas laysanensis & 12 & 3.35 & 2.91 & 0.99 \\
\hline Aves & Anas laysanensis & 12 & 2.89 & 2.60 & 0.99 \\
\hline Aves & Anser anser & 31 & 5.01 & 4.12 & 0.99 \\
\hline Aves & Anser anser & 31 & 6.54 & 5.71 & 0.99 \\
\hline Aves & Anser anser & 31 & 3.94 & 3.06 & 0.99 \\
\hline Aves & Anthropoides paradiseus & 27 & 4.54 & 4.14 & 0.96 \\
\hline Aves & Bonasa umbellus & 11 & 1.15 & 0.46 & 0.92 \\
\hline Aves & Bonasa umbellus & 11 & 0.90 & 0.27 & 0.77 \\
\hline Aves & Bonasa umbellus & 11 & 1.08 & 0.39 & 0.99 \\
\hline Aves & Bonasa umbellus & 11 & 1.25 & 0.54 & 0.94 \\
\hline Aves & Bonasa umbellus & 11 & 1.69 & 0.93 & 0.97 \\
\hline Aves & Bonasa umbellus & 11 & 1.21 & 0.51 & 0.91 \\
\hline Aves & Bonasa umbellus & 11 & 1.04 & 0.37 & 0.94 \\
\hline Aves & Bonasa umbellus & 11 & 1.05 & 0.38 & 0.88 \\
\hline Aves & Bostrychia hagedash & 16 & 3.19 & 2.36 & 1.00 \\
\hline Aves & Buteo solitarius & 17 & 1.88 & 1.31 & 0.82 \\
\hline Aves & Buteo solitarius & 17 & 4.06 & 3.75 & 0.99 \\
\hline Aves & Buteo solitarius & 17 & 2.67 & 2.28 & 0.93 \\
\hline Aves & Calidris temminckii & 12.9 & 2.64 & 1.83 & 1.00 \\
\hline Aves & Calyptorhynchus lathami & 44.47 & 6.91 & 6.08 & 0.97 \\
\hline
\end{tabular}




\begin{tabular}{|c|c|c|c|c|c|}
\hline Aves & $\begin{array}{c}\text { Campylorhynchus brunneicapillus subsp. } \\
\text { sandiegensis }\end{array}$ & 7.3 & 1.23 & 0.59 & 0.81 \\
\hline Aves & Centrocercus minimus & 7 & 1.11 & 0.43 & 0.98 \\
\hline Aves & Centrocercus minimus & 7 & 1.11 & 0.46 & 0.79 \\
\hline Aves & Certhia americana & 8.2 & 1.03 & 0.43 & 0.97 \\
\hline Aves & Chen caerulescens & 27.5 & 4.98 & 4.09 & 1.00 \\
\hline Aves & Falco naumanni & 10.9 & 1.52 & 0.85 & 0.83 \\
\hline Aves & Falco peregrinus subsp. anatum & 15.81 & 2.54 & 1.80 & 0.91 \\
\hline Aves & Fulmarus glacialis & 51 & 11.06 & 10.15 & 1.00 \\
\hline Aves & Gavia immer & 24.1 & 1.89 & 1.33 & 0.79 \\
\hline Aves & Gavia immer & 24.1 & 1.85 & 1.29 & 0.79 \\
\hline Aves & Gavia immer & 24.1 & 1.92 & 1.37 & 0.80 \\
\hline Aves & Gyps coprotheres & 30.55 & 6.53 & 5.80 & 0.98 \\
\hline Aves & Haliaeetus albicilla & 42 & 5.35 & 4.45 & 1.02 \\
\hline Aves & Haliaeetus albicilla & 42 & 4.66 & 3.77 & 1.00 \\
\hline Aves & Lagopus leucura & 15 & 0.94 & 0.31 & 0.74 \\
\hline Aves & Lagopus leucura & 15 & 1.00 & 0.35 & 0.78 \\
\hline Aves & Lagopus muta & 12 & 1.38 & 0.68 & 0.84 \\
\hline Aves & Lagopus muta & 12 & 1.17 & 0.51 & 0.76 \\
\hline Aves & Lagopus muta subsp. japonica & 12 & 2.25 & 1.42 & 1.17 \\
\hline Aves & Larus heermanni & 29.87 & 5.24 & 4.44 & 1.05 \\
\hline Aves & Milvus migrans & 24 & 2.38 & 1.63 & 0.91 \\
\hline Aves & Nipponia nippon & 25.8 & 2.73 & 1.90 & 1.02 \\
\hline Aves & Pernis apivorus & 29 & 5.00 & 4.10 & 1.01 \\
\hline Aves & Phalacrocorax auritus & 22.5 & 2.06 & 1.37 & 0.82 \\
\hline Aves & Sterna hirundo & 33 & 3.52 & 2.87 & 0.90 \\
\hline Aves & Sterna hirundo & 33 & 2.58 & 1.92 & 0.85 \\
\hline Aves & Sternula antillarum subsp. browni & 24 & 2.70 & 2.08 & 0.93 \\
\hline Aves & Strix occidentalis subsp. occidentalis & 22.22 & 4.06 & 3.21 & 0.99 \\
\hline Aves & Thalassarche melanophris & 43.7 & 2.32 & 1.57 & 0.76 \\
\hline Aves & Turdus torquatus & 9.1 & 0.57 & 0.05 & 0.22 \\
\hline Aves & Turdus torquatus & 9.1 & 0.61 & 0.07 & 0.28 \\
\hline Aves & Turdus torquatus & 9.1 & 0.55 & 0.03 & 0.15 \\
\hline Aves & Vermivora chrysoptera & 7.9 & 0.91 & 0.28 & 0.73 \\
\hline Mammalia & Alces alces & 29.75 & 5.28 & 4.49 & 0.99 \\
\hline Mammalia & Alces alces & 29.75 & 3.26 & 2.59 & 0.91 \\
\hline Mammalia & Alces alces & 29.75 & 4.63 & 3.76 & 1.62 \\
\hline Mammalia & Alces alces & 29.75 & 2.31 & 1.54 & 1.21 \\
\hline Mammalia & Brachyteles hypoxanthus & 40 & 7.94 & 7.78 & 1.00 \\
\hline Mammalia & Callorhinus ursinus & 21 & 4.30 & 3.52 & 1.00 \\
\hline Mammalia & Callospermophilus lateralis & 10.4 & 1.00 & 0.40 & 0.83 \\
\hline Mammalia & Canis lupus & 20.6 & 1.95 & 1.55 & 0.95 \\
\hline Mammalia & Capra ibex & 20.71 & 11.77 & 10.89 & 1.10 \\
\hline
\end{tabular}




\begin{tabular}{|c|c|c|c|c|c|}
\hline Mammalia & Capra ibex & 20.71 & 9.67 & 9.00 & 1.04 \\
\hline Mammalia & Capra ibex & 20.71 & 11.61 & 10.65 & 1.37 \\
\hline Mammalia & Capra ibex & 20.71 & 10.24 & 9.28 & 1.22 \\
\hline Mammalia & Cebus capucinus & 54 & 12.76 & 12.16 & 0.99 \\
\hline Mammalia & Cervus elaphus & 31.5 & 9.69 & 8.76 & 1.12 \\
\hline Mammalia & Cervus elaphus & 31.5 & 1.51 & 0.89 & 0.79 \\
\hline Mammalia & Cervus elaphus & 31.5 & 1.80 & 1.16 & 0.85 \\
\hline Mammalia & Cervus elaphus & 31.5 & 3.31 & 2.56 & 0.99 \\
\hline Mammalia & Elephas maximus & 65.5 & 28.40 & 27.68 & 1.01 \\
\hline Mammalia & Eumetopias jubatus & 32.8 & 3.38 & 2.53 & 0.99 \\
\hline Mammalia & Eumetopias jubatus & 32.8 & 5.40 & 4.57 & 0.96 \\
\hline Mammalia & Eumetopias jubatus & 32.8 & 6.47 & 5.59 & 1.21 \\
\hline Mammalia & Eumetopias jubatus & 32.8 & 3.32 & 2.48 & 1.44 \\
\hline Mammalia & Gorilla beringei & 60.1 & 17.26 & 16.83 & 1.00 \\
\hline Mammalia & Gorilla beringei & 60.1 & 15.15 & 14.70 & 1.00 \\
\hline Mammalia & Halichoerus grypus & 42.9 & 8.28 & 7.53 & 0.98 \\
\hline Mammalia & Leptonychotes weddellii & 48.13 & 4.67 & 3.87 & 0.92 \\
\hline Mammalia & Macaca mulatta & 40 & 11.24 & 10.73 & 1.00 \\
\hline Mammalia & Macaca mulatta & 40 & 11.46 & 10.84 & 1.00 \\
\hline Mammalia & Macaca mulatta & 40 & 10.47 & 10.07 & 1.00 \\
\hline Mammalia & Macaca mulatta & 40 & 11.27 & 10.63 & 1.00 \\
\hline Mammalia & Marmota flaviventris & 21.2 & 1.64 & 0.92 & 0.91 \\
\hline Mammalia & Mirounga leonina & 39 & 4.88 & 3.99 & 0.98 \\
\hline Mammalia & Mustela erminea & 12.5 & 1.02 & 0.36 & 0.75 \\
\hline Mammalia & Odocoileus virginianus & 23 & 2.13 & 1.49 & 0.78 \\
\hline Mammalia & Onychogalea fraenata & 7.4 & 2.52 & 1.94 & 0.99 \\
\hline Mammalia & Orcinus orca & 90 & 22.39 & 21.49 & 1.01 \\
\hline Mammalia & Orcinus orca & 90 & 20.19 & 19.30 & 1.00 \\
\hline Mammalia & Orcinus orca & 90 & 24.83 & 23.94 & 1.01 \\
\hline Mammalia & Ovis aries & 22.8 & 4.00 & 3.25 & 0.95 \\
\hline Mammalia & Ovis canadensis subsp. sierrae & 19.95 & 5.00 & 4.48 & 0.98 \\
\hline Mammalia & Ovis canadensis subsp. sierrae & 19.95 & 5.01 & 4.49 & 0.98 \\
\hline Mammalia & Ovis canadensis subsp. sierrae & 19.95 & 3.53 & 3.41 & 1.00 \\
\hline Mammalia & Ovis canadensis subsp. sierrae & 19.95 & 3.96 & 3.24 & 0.96 \\
\hline Mammalia & Ovis canadensis subsp. sierrae & 19.95 & 4.85 & 4.25 & 0.98 \\
\hline Mammalia & Ovis canadensis subsp. sierrae & 19.95 & 3.51 & 2.77 & 0.95 \\
\hline Mammalia & Ovis canadensis subsp. sierrae & 19.95 & 4.35 & 3.63 & 0.97 \\
\hline Mammalia & Ovis canadensis & 19.95 & 5.57 & 4.80 & 1.01 \\
\hline Mammalia & Ovis canadensis & 19.95 & 4.40 & 3.60 & 0.99 \\
\hline Mammalia & Ovis canadensis & 19.95 & 4.97 & 4.18 & 1.00 \\
\hline Mammalia & Ovis canadensis & 19.95 & 4.87 & 4.01 & 1.03 \\
\hline Mammalia & Pan troglodytes subsp. schweinfurthii & 57.2 & 16.61 & 15.82 & 1.00 \\
\hline Mammalia & Panthera pardus & 27.3 & 2.43 & 1.70 & 0.84 \\
\hline
\end{tabular}


bioRxiv preprint doi: https://doi.org/10.1101/819565; this version posted October 28,2019 . The copyright holder for this preprint (which was not certified by peer review) is the author/funder, who has granted bioRxiv a license to display the preprint in perpetuity. It is made available under aCC-BY-NC 4.0 International license.

\begin{tabular}{|c|c|c|c|c|c|}
\hline Mammalia & Papio cynocephalus & 37.5 & 9.41 & 8.83 & 0.99 \\
\hline Mammalia & Phoca vitulina & 47.6 & 2.09 & 1.27 & 1.08 \\
\hline Mammalia & Phoca vitulina & 47.6 & 2.29 & 1.46 & 1.37 \\
\hline Mammalia & Phocarctos hookeri & 26 & 5.64 & 4.75 & 1.06 \\
\hline Mammalia & Presbytis thomasi & 20 & 4.07 & 3.29 & 0.97 \\
\hline Mammalia & Propithecus edwardsi & 24 & 4.08 & 3.51 & 0.94 \\
\hline Mammalia & Propithecus verreauxi & 31 & 9.11 & 8.46 & 1.00 \\
\hline Mammalia & Rangifer tarandus & 21.8 & 2.91 & 2.35 & 0.94 \\
\hline Mammalia & Rangifer tarandus & 21.8 & 3.88 & 3.37 & 0.98 \\
\hline Mammalia & Rangifer tarandus subsp. platyrhynchus & 21.8 & 7.98 & 7.40 & 1.02 \\
\hline Mammalia & Sousa chinensis & 50.39 & 9.71 & 8.79 & 1.21 \\
\hline Mammalia & Sousa chinensis & 50.39 & 9.67 & 8.75 & 1.21 \\
\hline Mammalia & Tamiasciurus hudsonicus & 9.8 & 1.32 & 0.65 & 1.02 \\
\hline Mammalia & Urocitellus armatus & 9 & 1.09 & 0.41 & 0.92 \\
\hline Mammalia & Urocitellus beldingi & 9 & 3.25 & 2.53 & 1.11 \\
\hline Mammalia & Ursus americanus & 34 & 3.53 & 2.81 & 0.92 \\
\hline Mammalia & Ursus americanus & 34 & 3.37 & 2.54 & 0.92 \\
\hline Mammalia & Ursus arctos subsp. horribilis & 39.25 & 4.62 & 3.71 & 1.01 \\
\hline Mammalia & Zalophus californianus & 35.7 & 5.34 & 4.49 & 1.02 \\
\hline Mammalia & Zalophus californianus & 35.7 & 4.12 & 3.28 & 1.09 \\
\hline Reptilia & Chrysemys picta & 61 & 3.13 & 2.28 & 2.38 \\
\hline Reptilia & Chrysemys picta & 61 & 1.43 & 0.79 & 0.64 \\
\hline Reptilia & Crocodylus johnsoni & 47.34 & 1.79 & 1.16 & 0.75 \\
\hline Reptilia & Crocodylus johnsoni & 47.34 & 2.48 & 1.83 & 0.83 \\
\hline Reptilia & Crocodylus johnsoni & 47.34 & 1.35 & 0.76 & 0.66 \\
\hline Reptilia & Cryptophis nigrescens & 21 & 1.67 & 0.98 & 0.81 \\
\hline Reptilia & Hoplocephalus bungaroides & 31 & 2.64 & 1.85 & 0.88 \\
\hline Reptilia & Kinosternon subrubrum & 40 & 1.62 & 0.96 & 0.72 \\
\hline Reptilia & Kinosternon subrubrum & 40 & 0.80 & 0.21 & 0.36 \\
\hline Reptilia & Kinosternon subrubrum & 40 & 3.15 & 2.42 & 0.89 \\
\hline
\end{tabular}

